\title{
Do nuclear envelope and intranuclear proteins reorganize during mitosis to form an elastic, hydrogel-like spindle matrix?
}

\author{
Kristen M. Johansen • Arthur Forer • \\ Changfu Yao • Jack Girton • Jørgen Johansen
}

Published online: 28 January 2011

(C) Springer Science+Business Media B.V. 2011

\begin{abstract}
The idea of a spindle matrix has long been proposed in order to account for poorly understood features of mitosis. However, its molecular nature and structural composition have remained elusive. Here, we propose that the spindle matrix may be constituted by mainly nuclear-derived proteins that reorganize during the cell cycle to form an elastic gel-like matrix. We discuss this hypothesis in the context of recent observations from phylogenetically diverse organisms that nuclear envelope and intranuclear proteins form a highly dynamic and malleable structure that contributes to mitotic spindle function. We suggest that the viscoelastic properties of such a matrix may constrain spindle length while at the same time facilitating microtubule growth and dynamics as well as chromosome movement. A corollary to this hypothesis is that a key determinant of spindle size may be the amount of nuclear proteins available to form the spindle matrix. Such a matrix could also serve as a spatial regulator of spindle assembly checkpoint proteins during open and semi-open mitosis.
\end{abstract}

Responsible Editor: James Wakefield and Herbert Macgregor.

K. M. Johansen $\cdot$ C. Yao $\cdot$ J. Girton $\cdot$ J. Johansen $(\bowtie)$

Department of Biochemistry, Biophysics,

and Molecular Biology, Iowa State University,

3156 Molecular Biology Building,

Ames, IA 50011, USA

e-mail: jorgen@iastate.edu

A. Forer

Biology Department, York University,

Toronto, Ontario M3J 1P3, Canada
Keywords spindle matrix $\cdot$ mitosis $\cdot$ nuclear reorganization nuclear envelope $\cdot$ nucleoporins . microtubules

$\begin{array}{ll}\text { Abbreviations } \\ \text { ER } & \text { Endoplasmic reticulum } \\ \text { FN } & \text { Fibronectin } \\ \text { Ig } & \text { Immunoglobulin } \\ \text { NMR } & \text { Nuclear magnetic resonance } \\ \text { NPC } & \text { Nuclear pore complex } \\ \text { Nups } & \text { Nucleoporins } \\ \text { FG } & \text { Phenylalanine-glycine } \\ \text { PAR } & \text { Poly(ADP-ribose) } \\ \text { PARG } & \text { Poly(ADP-ribose) glycohydrolase } \\ \text { PARP } & \text { Poly(ADP-ribose) polymerase } \\ \text { Tpr } & \text { Translocated promoter region protein } \\ \text { UV } & \text { Ultraviolet }\end{array}$

\section{Introduction}

A basic element of cell division is the formation of a mitotic spindle that helps segregate the duplicated chromosomes to the daughter nuclei. Although a variety of approaches have been applied over the past century to the investigation of this remarkable structure, in recent years, its study has been facilitated by the very powerful approach of using a concentrated Xenopus laevis cytoplasmic extract that closely mimics certain in vivo conditions yet still allows the classical reductionist in 
vitro approach of depleting or perturbing individual constituents (Lohka and Maller 1985; Sawin and Mitchison 1991; Desai et al. 1999). Indeed, such manipulations have addressed mechanisms underlying a variety of fascinating spindle features such as poleward microtubule flux (Mitchison 2005) and have uncovered unanticipated findings such as that a bipolar spindle can form and function despite the absence of chromosomes and their kinetochore targets (Heald et al. 1996). This has been an especially tractable system in which to study the dynamics of spindle microtubules, arguably the "centerpiece" of the mitotic spindle. In fact, many popular textbooks still describe the "mitotic spindle" in terms only of microtubules and their associated motor proteins. However, more recently, this system has begun to uncover additional requirements for proper spindle functions for proteins other than tubulin and motor proteins (reviewed in Johansen and Johansen 2007, 2009; De Souza and Osmani 2009; Zheng 2010).

The idea of a "spindle matrix" has been long proposed to help account for a number of experimentally observed properties of spindle behavior as well as theoretical considerations that cannot be explained by microtubule behavior alone (reviewed in Pickett-Heaps et al. 1982; Pickett-Heaps et al. 1997; Johansen and Johansen 2002, 2007, 2009). A large number of studies spanning from early microscopy studies in the 1960s (Forer and Goldman 1969) to recent proteomic analysis (Sauer et al. 2005; Han et al. 2010) confirm that the spindle is a very complex structure containing significantly more than microtubules. A "spindle remnant" can be isolated in the absence of microtubules (Rebhun and Palazzo 1988; Leslie et al. 1987; Wein et al. 1998) and in Drosophila, nuclear proteins (e.g., Megator, Skeletor, Chromator, and EAST) have been shown to adopt a spindle-like structure that can persist independently of the microtubule spindle (Walker et al. 2000; Rath et al. 2004; Qi et al. 2004, 2005). Chromosomes still move poleward even after the kinetochore microtubules have been severed using a ultraviolet (UV) microbeam (Sillers and Forer 1983; Spurck et al. 1997; Forer et al. 2007). Coupled with the recent finding in fission yeast that chromosome separation and nuclear division can occur despite the complete absence of spindle microtubules (Castagnetti et al. 2010), a strong case can be made for the existence of additional components partaking in chromosome segregation mechanisms.
Perhaps one reason why identification and functional analysis of these "additional components" has been so elusive is that many of these components appear to play critical roles in nuclear organization and function during interphase. Thus, it can be difficult to isolate and characterize their roles in spindle assembly and function if their removal or perturbation were to compromise other processes at different cell cycle stages. However, recent advances in cell imaging techniques combined with molecular and genetic approaches have begun to allow for a detailed investigation of these proteins' roles during mitosis. Here, we review evidence supporting the hypothesis that a non-microtubule entity such as the proposed spindle matrix contributes to mitotic spindle function, and we discuss molecular candidates comprising such a structure. We propose that many if not most of the proteins comprising this structure originate from the nucleus and suggest that although the nuclear architecture has traditionally been considered to "disassemble" during mitosis, it may be more accurate to characterize it as being "remodeled" during the cell cycle.

\section{Early observations pointing toward the existence of a spindle matrix}

Some of the first experimental observations that hinted at the existence of a spindle matrix were from the early experiments of Kane and Forer (1965) and Goldman and Rebhun (1969), who found that the volume of the nonmicrotubule portion of the spindle was much greater than that of the microtubules in isolated mitotic apparatuses from sea urchin zygotes. These mitotic apparatuses contained microtubule arrays that appeared the same as in living cells, but they also contained nonmicrotubule components that kept the spindle shape even after the microtubules were depolymerized (Kane and Forer 1965; Goldman and Rebhun 1969; Steffen and Linck 1992). Moreover, the non-microtubule material bound kinesin leading to the suggestion that it might act in vivo as a "matrix" that surrounds and acts on spindle microtubules (Leslie et al. 1987; Pickett-Heaps et al. 1984). Subsequent experiments with diatom spindles further pointed to the existence of an elastic matrix underlying the proper function of spindle microtubules. Mitotic cells in diatoms such as Hantzschia have a central spindle, which consists of interdigitating microtubules from the two poles, 
together with polar microtubules that extend from each pole toward the metaphase chromosomes. In these spindles, the ends of the polar microtubules do not attach to the kinetochores but rather extend past them (Pickett-Heaps and Tippit 1980a, b; Tippit et al. 1980). Thus, the kinetochores of each chromosome are stretched in opposite directions along the spindle axis in association with an electron-dense "collar" which extends from each pole. Interestingly, colchicine treatment had no effect on central spindle microtubules but caused the microtubules associated with the chromosomes to disappear, after which individual chromosomes detached from one of the two poles and moved to the other while remaining connected to the "collar." Based on these observations, Pickett-Heaps and colleagues proposed a model where this collar may constitute a contractile "matrix" and where microtubules from the poles counteract forces from the collar that would pull the chromosomes poleward (Pickett-Heaps and Tippit 1980a, b; Tippit et al. 1980). Consequently, when the polar microtubules are depolymerized, the collar contracts and takes kinetochores with them to the poles. A caveat to a potential general significance of these experiments is that diatom spindles are unique in that polar microtubules do not attach directly to the kinetochores. However, similar observations with more conventional spindles suggest that a contractile matrix might be a general feature of mitosis (reviewed in Pickett-Heaps et al. 1982, 1984).

A completely different line of experiments also pointed to the existence of a possible elastic matrix. Ultraviolet microbeam irradiations across an entire half spindle destroy all the microtubules in the irradiated region as seen by electron microscopy; hence, the pole is severed from microtubule connections with the rest of the spindle. Nonetheless, spindle poles move toward the equator after the irradiation (Spurck et al. 1990; Snyder et al. 1991) by "unknown mechanisms" (Spurck et al. 1990), suggesting there is an elastic force acting on the spindle pole that is responsible for moving it towards the spindle. In addition, if microtubules are responsible for poleward forces and the equatorial position in metaphase is because of a balance of forces toward the two poles, then severing a kinetochore fiber should block force from that pole and thereby produce an imbalance of forces; hence the chromosome should move off the equator toward the non-severed fiber. However, severing kinetochore microtubules in metaphase newt fibroblasts causes the chromosome attached to the irradiated fiber (and its attached kinetochore fiber stub) to move toward the pole on the irradiated side, that is, the pole toward which the severed fiber (kinetochore stub) is directed (Spurck et al. 1997). Movement ceases once the kinetochore stub reaches the pole. This is opposite to what would be predicted by most current models, and it suggests that poleward directed forces arising external to microtubules (e.g., from a spindle matrix) acts on the chromosomes and their kinetochore fibers. The kinetochore microtubules ordinarily resist these forces, but once the kinetochore microtubules are severed, the forces propel the kinetochore stub and chromosome to the pole. When the stub reaches the pole, the stub microtubules counteract the poleward forces from the spindle matrix and motion slows again. Severing of kinetochore microtubules in anaphase newt fibroblasts causes the associated chromosome (and its stub) to accelerate poleward, ahead of the other anaphase chromosomes, until the stub reaches the pole (Spurck et al. 1997). Similar results were obtained in grasshopper spermatocytes (Gordon 1980; Gordon and Inoué 1979; Izutsu 1988; Chen and Zhang 2004). Since microtubule depolymerisation is the rate limiting step for anaphase chromosome movements (Forer 1974; Nicklas 1975, 1983; Inoué and Ritter 1975; PickettHeaps et al. 1982), the results from the irradiations all point to the idea that extrinsic components to the microtubules produce poleward directed forces that drive the chromosomes poleward. As further indication that the forces arise external to the kinetochore microtubules, microtubules in the path of the accelerating chromosomes-and-stubs are bent (Pickett-Heaps et al. 1996), as are microtubules in Xenopus extract spindles when poles move together during slow microtubule depolymerization (Mitchison et al. 2005).

This experimental paradigm now has been repeated in other cell types. For example, when metaphase kinetochore microtubules are severed in Drosophila S2 cells (Maiato et al. 2004) or crane-fly spermatocytes (Forer 1965), the associated metaphase chromosomes do not move off the equator, contrary to expectations, and there is no change in inter-kinetochore distance. This shows that in these cells, forces on the chromosome from the kinetochore stub are equivalent to those from the nonsevered fiber to the opposite pole (Maiato et al. 2004). When anaphase kinetochore microtubules are severed in crane-fly spermatocytes, the chromosomes that continue to move poleward do not accelerate but rather move at 
normal (unchanged) velocity. This argues against microtubules as being the motor that drives the movement and, despite the lack of acceleration, can be interpreted as being due to the kinetochore stub being propelled poleward by extrinsic forces (Forer et al. 2003).

Thus, many of these phenomena raise questions that are unanswered by conventional models of spindle function; for example, that metaphase chromosomes would move toward the irradiated pole, that anaphase chromosomes would accelerate, or that intervening microtubules would be bent strongly all suggest that forces act on the kinetochore microtubules and are not produced by them directly. We suggest a compelling answer may be the existence of a spindle matrix that is independent of the microtubule-based spindle apparatus. However, at present, the molecular composition and biophysical properties of such a potential matrix is unclear and one of the major challenges is to define what a spindle matrix is.

\section{What is the matrix?}

I know why you're here, Neo. I know why.... night after night you sit at your computer. ....It's the question that drives us, Neo. It's the question that brought you here. You know the question, just as I did.

\section{What is the Matrix?}

The answer is out there, Neo. It's looking for you. And it will find you if you want it to.

\section{-Wachowski, A. and Wachowski, L. The Matrix, 1999}

The concept of a spindle matrix, though gaining traction in recent years, has for many years remained a controversial topic. Some of this may be due to an admittedly incomplete understanding of the molecular composition and emergent properties of such a matrix. As well, early hypotheses necessarily require revisions as additional information is gained. But much of the resistance seems also to be due to semantics, as the term "matrix" conjures up distinct meanings for different people. This is perhaps because the dictionary definition of "matrix" as "a substance, situation, or environment in which something has its origin, takes form, or is enclosed" (The Merriam-Webster Unabridged Dictionary) is not particularly restrictive. Thus, while we do not as yet have a complete understanding of the exact architecture of the spindle matrix, the accruing data indicate that the matrix is not a rigid substrate. For example, in Drosophila, when microtubules are depolymerized the Megator-defined spindle matrix compresses (Qi et al. 2004; Lince-Faria et al. 2009), suggesting that the spindle matrix structure itself is elastic. Mechanical probing of spindles assembled in Xenopus extracts revealed that microneedle-skewered spindles can translocate along the interpolar axis at a velocity slightly slower than microtubule poleward flux (Gatlin et al. 2010). Although these latter experiments have the caveat that in vitro assembled spindles may lack certain components such as actin that potentially could play a structural role, collectively, the data indicate the spindle matrix is comprised of a very dynamic and flexible structure. Thus, a reasonable question might be whether there is an alternative type of organization other than a rigid, cross-linked filament system that could confer the kinds of properties envisioned for a spindle matrix yet be consistent with the currently available data. We find it useful to consider what is known about the molecular properties of the nuclear pore complex (NPC), especially given that we now know that some NPC proteins act as spindle matrix proteins during mitosis (De Souza and Osmani 2009).

The nuclear pore complex is one of the largest macromolecular complexes in biology consisting of an 8 -fold symmetrical structure built from about 30 different proteins collectively called nucleoporins (Nups), many of which are present in multiple copies (reviewed in Baktrakou et al. 2009). There are three main parts: a central core in the plane of the nuclear envelope, a nuclear basket, and cytoplasmic filaments. Whereas some nucleoporins form a rigid scaffold structure, $\sim 12-20 \%$ of the mass of a NPC consists of the so-called FG-Nups that are characterized by domains of unstructured and highly disordered phenylalanine-glycine (FG) repeats (Rout et al. 2000; Denning et al. 2003). These domains are proposed to promote intra- and intermolecular cohesion to form a malleable yet cohesive quaternary structure. Two competing models describe the behavior of these highly flexible polypeptide domains. In the elastic "hydrogel" model, they are proposed to comprise a three-dimensional network of hydrophobic clusters with gel-like properties (Frey et al. 2006; Krishnan et al. 2008); indeed, a single Nup FG-repeat domain is able reproduce a hydrogel with permeability 
properties of the NPC (Frey and Görlich 2007). An alternate model favors a more "brushlike structure" of aggregated FG-Nups with compressive properties (Miao and Schulten 2010).

The presence of multiple FG-repeat proteins provides redundancy to essential barrier functions within an aqueous channel (Strawn et al. 2004), although the complexity and redundancy of FG-Nups has made it difficult to study their roles in vivo in metazoans (reviewed in Terry and Wente 2009). Nevertheless, in vitro and in vivo studies in yeast support a model in which the conformational flexibility inherent to these domains facilitates collapse of the three-dimensional sieve-like barrier when in contact with nuclear transport receptors, thus transiently opening the mesh (Frey and Görlich 2009; Miao and Schulten 2010). Although such disordered structures are not amenable to standard structural analysis techniques, recent studies using solid state NMR indicate that the NQTS-rich spacers in the FG domain contribute to barrier function by forming amyloid-like interchain $\beta$-structures that suppress passage of large inert molecules (Ader et al. 2010). Although these amyloidlike fibers are kinetically the most stable structures within the FG hydrogel, rapid fluctuations of the hydrophobic interactions between the FG repeats prevent irreversible aggregation of the amyloid-like fibers, thus maintaining a structure that can still be collapsed (Ader et al. 2010).

Intriguingly, a number of NPC proteins have been found to localize to the mitotic spindle. The best studied is Megator, the Drosophila Tpr (translocated promoter region protein) homolog, which exhibits a number of properties consistent with a spindle matrix (Zimowska et al. 1997; Qi et al. 2004; Lince-Faria et al. 2009; see below). The spindle localization of Tpr is conserved across evolution (see below). Tpr has a long N-terminal coiled coil domain and an unstructured C-terminal domain (Mitchell and Cooper 1992), so it is not an obvious candidate to confer gel-like or brushlike properties. However, FG-Nups that have thus far been observed to localize to the spindle include Nup153 (Katsani et al. 2008), Nup214 (Hashizume et al. 2010) and Nup358 (=RanBP2) (Joseph et al. 2002). The GLFG-Nup98 has also been observed to disperse broadly throughout the cell during mitosis, including throughout the spindle region in an overlapping pattern with Rael (Xu and Powers 2010). Rae1 is a microtubule-associated protein that acts as a spindle assembly factor (Blower et al. 2005). Disruption of Nup214 localization results in multipolar spindles and chromosome separation defects (Hashizume et al. 2010) whereas Nup358 depletion perturbs chromosome congression and segregation (Salina et al. 2003). Nup98 associates with intranuclear Tpr (Fontoura et al. 2001) and although it is not known if this association continues in mitosis, mitotic Nup98 has been shown to form a complex with Rae1 and APC ${ }^{\mathrm{Cdh} 1}$ (Cdh1-activated anaphase promoting complex). Haploinsufficient Nup $98^{+/-} /$Rael $^{+/-}$mice exhibit premature separation of sister chromatids and severe aneupoloidy due to untimely degradation of securin (Jeganathan et al. 2005). In addition, non-FG nucleoporins in the Nup $107 / 160$ complex localize to kinetochores, spindle poles, and proximal spindle fibers (Orjalo et al. 2006; Katsani et al. 2008; Mishra et al. 2010) and Nup88 colocalizes with Nup214 on the spindle bodies (Hashizume et al. 2010). The Nup107/160 complex appears to play a role in assembly or maintenance of spindle fibers between the poles and chromosomes (Orjalo et al. 2006) whereas loss of Nup88 results in Nup214 depletion from the spindle and multipolar spindles (Hashizume et al. 2010).

Thus, a gel-like spindle matrix would be predicted to be capable of conferring the elastic, malleable properties that have been observed, for example, in its rapid compression upon disassembly of the microtubules in Drosophila S2 cells by Lince-Faria et al. (2009). Furthermore, like the nuclear pore complex, a spindle matrix could serve as a barrier to some cellular components while being permeable to others. For example, a gel-like spindle matrix could act as a barrier to exclude organelles such as mitochondria from the chromosomal division arena, much like a dense, cross-linked actin meshwork does at the cell cortex (Morone et al. 2006). At the same time, a gel-like structure would need to be permeable and rapidly collapse and remodel around other substrates, for example as would need to occur to allow focusing of the spindle poles, integration of chromosome-initiated microtubules into the spindle body, and movement of both structural and regulatory factors as well as chromosomes on the spindle by motor proteins. The spindle matrix may even be envisioned to contribute directly to building of the microtubule structure: Nup $107 / 60$ interacts with $\gamma$-TuRC and recruits it to unattached kinetochores where microtubules can be 
nucleated in a manner regulated by RanGTPase (Mishra et al. 2010). Although a role for Nup358 in mitotic microtubule dynamics has not yet been explored, in its position on the cytoplasmic face of the NPC at interphase, it interacts with microtubules and overexpression of Nup358's MT-binding domain results in increased microtubule stability and bundling (Joseph and Dasso 2008). All these data show that NPCs and Nups contribute to spindle function, and we propose that this is because they reorganize after nuclear membrane breakdown to form part of the spindle matrix.

\section{Recent experimental data in the context of a gel-like, elastic matrix}

\section{The spindle matrix in Drosophila}

In Drosophila, nuclear proteins from two different compartments reorganize during prophase into a spindle-like structure that shows a number of properties consistent with a spindle matrix (reviewed in Johansen and Johansen 2007; 2009) including that the spindle-like structure persists even after microtubule disassembly (Walker et al. 2000; Qi et al. 2004) and that mitotic spindle defects are observed upon loss of EAST, Megator, or Chromator function in germline mosaic, RNAi depletion, or mutant studies (Wasser and Chia 2003; Qi et al. 2004; Lince-Faria et al. 2009; Ding et al. 2009). During interphase, two of the proteins, Skeletor and Chromator, are chromosomal (Walker et al. 2000; Rath et al. 2004) while two, EAST and Megator, are found in the extrachromosomal domain (Zimowska et al. 1997; Qi et al. 2004, 2005). Megator is also found in the nuclear pore complex (Zimowska et al. 1997). The presence of a large N-terminal coiled-coil domain in Megator raises the intriguing possibility that Megator could comprise a structural element of the spindle matrix complex. The other proteins, however, are low complexity and bioinformatic programs such as ProteinPredict (Rost et al. 2004) indicate they are likely to be largely unstructured, as is also true for the C-terminal domain of Megator.

In fixed preparations, it was observed that the nuclear proteins Skeletor, Chromator, EAST, and Megator began to form a spindle-like structure during prophase and prometaphase at a time when there was no significant evidence of a microtubule spindle penetrating within the nucleus (Walker et al. 2000; Rath et al. 2004; Qi et al. 2004, 2005). This nuclear spindle, however, was always oriented with respect to the separating centrosomes, implying some kind of relationship with the microtubule cytoskeleton (Walker et al. 2000). One possibility is that the two structures are coordinated across the nuclear envelope, perhaps via transmembrane nuclear envelope proteins such as SUN-KASH complex proteins (Fridkin et al. 2009). However, since early in Drosophila mitosis, the nuclear envelope and lamina becomes porous (Paddy et al. 1996), another possibility that cannot be excluded is that the earliest forming spindle microtubules had invaded the nuclear space but were not stabilized under the fixation conditions used. For this reason, a liveimaging approach using fluorescently tagged spindle matrix proteins and tubulin has been initiated to assess the dynamics of both microtubules and matrix proteins during formation of the mitotic spindle. Such dual-imaging studies of Chromator-GFP and $\alpha$-tubulin-mCherry suggests that whereas Chromator reorganizes away from the chromosomes as they begin to condense to fill the entire nuclear space, there is no obvious spindle-like morphology until the microtubules begin invading the nuclear space (Fig. 1). Based on these observations, we propose that the spindle matrix exists as a malleable gel-like structure that reorganizes in response to the incoming microtubules, thereby giving rise to a spindle-like appearance.

Since matrix organization (that is rearrangement of Chromator into a spindle shape) seems to occur only after interaction with microtubules, the question arises as to whether spindle matrix proteins form an "independent structure" or whether they are simply additional examples of the class of "microtubuleassociated proteins." Several lines of evidence support the notion that the spindle matrix is an independent structure. Firstly, when microtubules are disassembled using drugs or cold treatment, the spindle matrix

Fig. 1 Timelapse imaging of Chromator-GFP and tubulinmCherry in syncytial Drosophila embryos. The image sequence illustrates the dynamic relationship of the spindle matrix protein Chromator (in green) relative to microtubule spindle formation (in red). The results suggest that the spindle matrix is present within the nucleus prior to invasion of microtubules into the nuclear space. The movie from which these images are derived is available in the Supplementary Material and was obtained as described in Ding et al. (2009). Scale bar $=10 \mu \mathrm{m}$ 


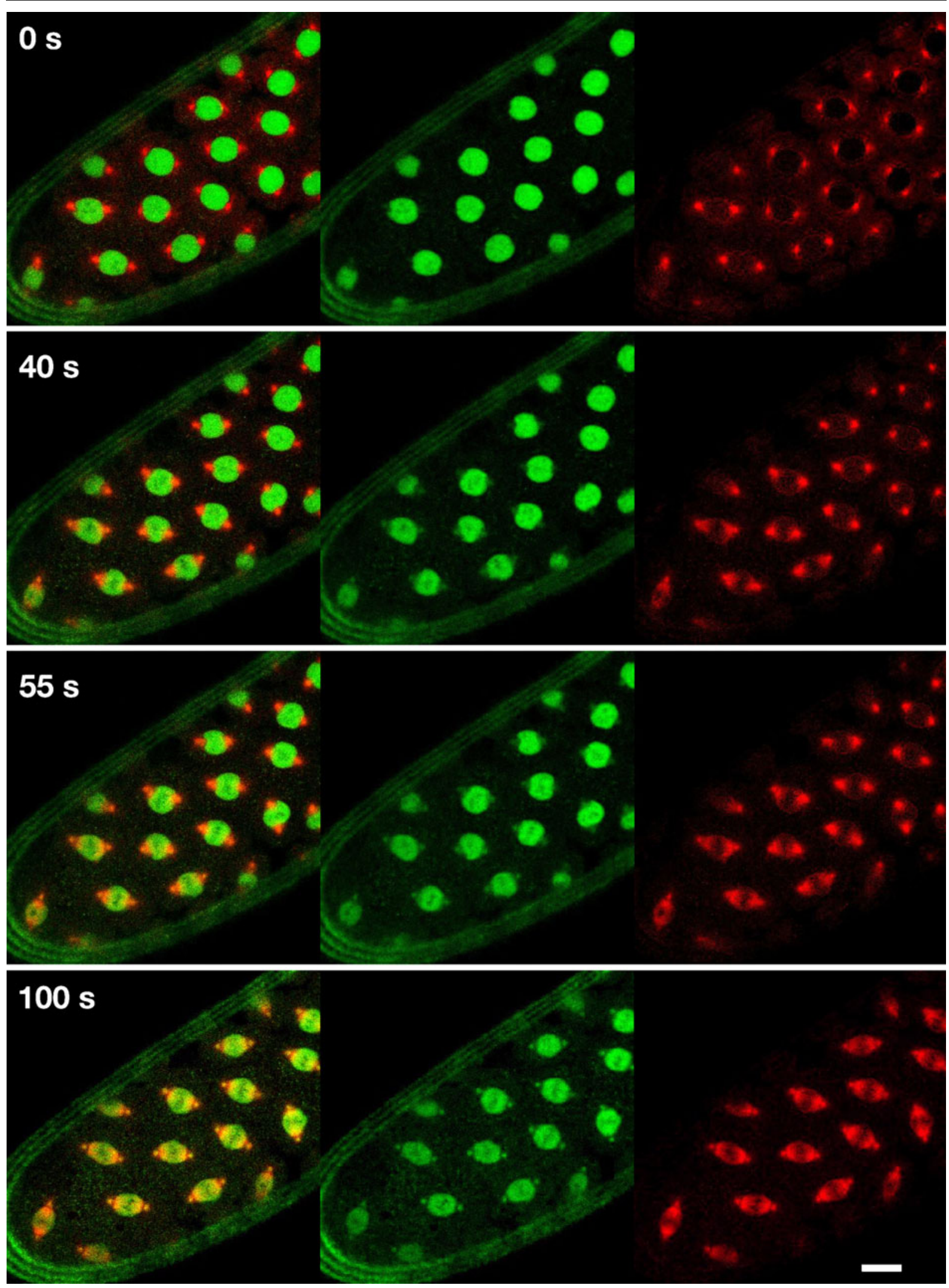


structure containing Skeletor or Megator persists, albeit in a compressed state (Walker et al. 2000; Qi et al. 2004) (Fig. 2), whereas, for example, the microtubuleassociated protein Jupiter does not (Lince-Faria et al. 2009). Secondly, measuring fluorescence intensities across the width of an individual spindle structure immunostained with both anti- $\alpha$-tubulin and Skeletor antibodies detected by different fluorophores reveals that the peaks of tubulin labeling are notably distinct from the peaks of Skeletor labeling (Fig. 3). This pattern, although not conclusive, is consistent with what might be observed for a gel-like matrix that embeds around an invading microtubule spindle structure.

Probing of the mechanical properties of the spindle in the in vitro Xenopus spindle assembly system

A recent effort (Gatlin et al. 2010) to query how in vitro-assembled spindles maintain a steady-state length, used microneedles to skewer in vitro assembled spindles to assess their mechanical properties and probe for the potential existence of an isotropic spindle matrix.
Once skewered, the spindle moved along the interpolar axis at a velocity slightly slower than microtubule poleward flux and further slowed as it approached the pole, although it was not clear whether slowing was due to impedance by pericentriolar spindle matrix components such as NuMA or because microtubule sliding is intrinsically slower at the poles. In most cases, the pole then splits apart, releasing the spindle. In cases where pole formation (and NuMA recruitment; Merdes et al. 1996; 2000) was disrupted by dynein inhibition, poles remained splayed out and slowing did not occur. Further experiments were performed using two skewering needles to stretch the spindle either longitudinally or transversely. Whereas longitudinal stretching did not show any obvious changes until the needles were close to the pole regions where some spindle stretching did occur, transverse stretching showed dramatic effects on the overall spindle dimensions, causing the two poles to be pulled closer together as the width of the spindle increased (Gatlin et al. 2010). From these results, the authors suggest there does not exist a strong isotropic spindle matrix that could account for the observed steady-state

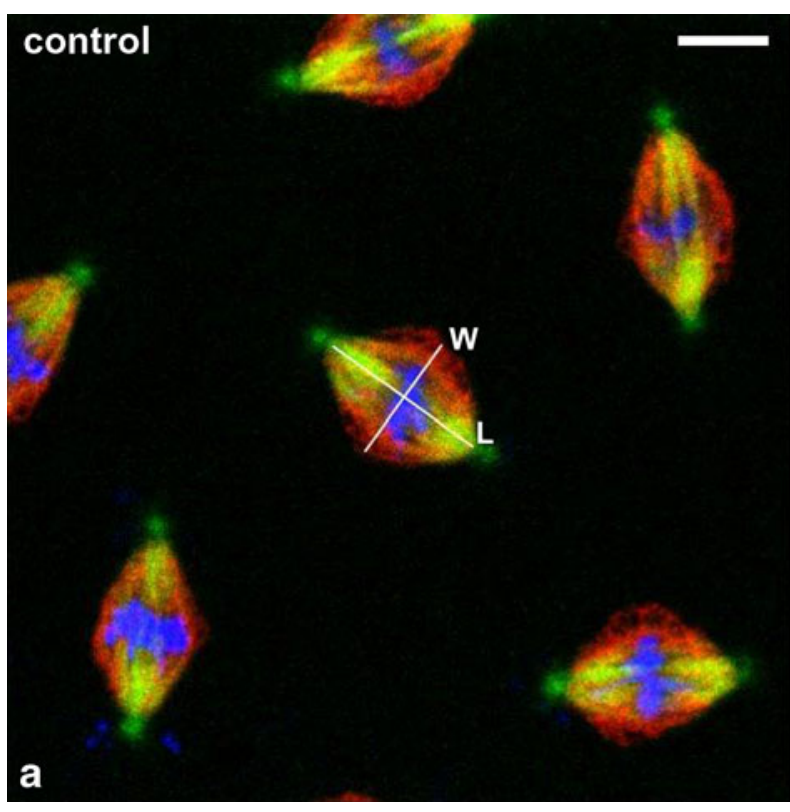

Fig. 2 Depolymerization of microtubules leads to compression of the spindle matrix. a Control embryo at metaphase triplelabeled with an antibody (mAb 1A1) specific for the spindle matrix protein Skeletor (in red), with tubulin antibody (in green), and with Hoechst (in blue). b Metaphase embryo labeled as in (a) but after depolymerization of microtubules by Nocodazole treatment. The length $(L)$ and width $(W)$ of the

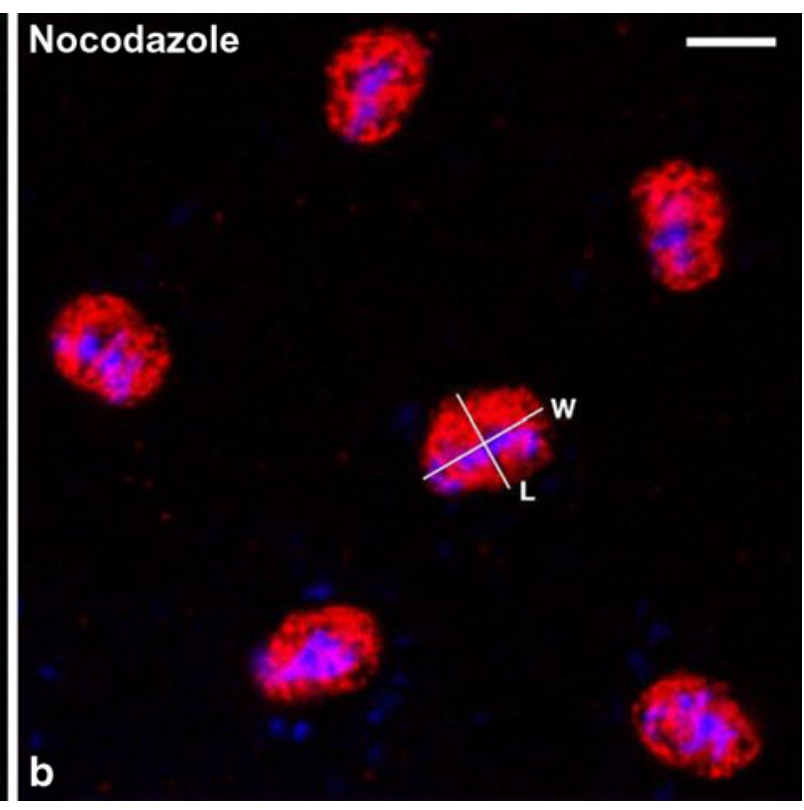

spindle matrix relative to the spindle axis are indicated by white lines. The $\mathrm{L} / \mathrm{W}$ ratio was reduced almost $60 \%$ in Nocodazoletreated embryos $(0.61 \pm 0.07, n=6)$ as compared to control embryos $(1.44 \pm 0.18, n=5)$. The confocal images shown are from preparations obtained as described in Walker et al. (2000). Scale bar $=5 \mu \mathrm{m}$ 


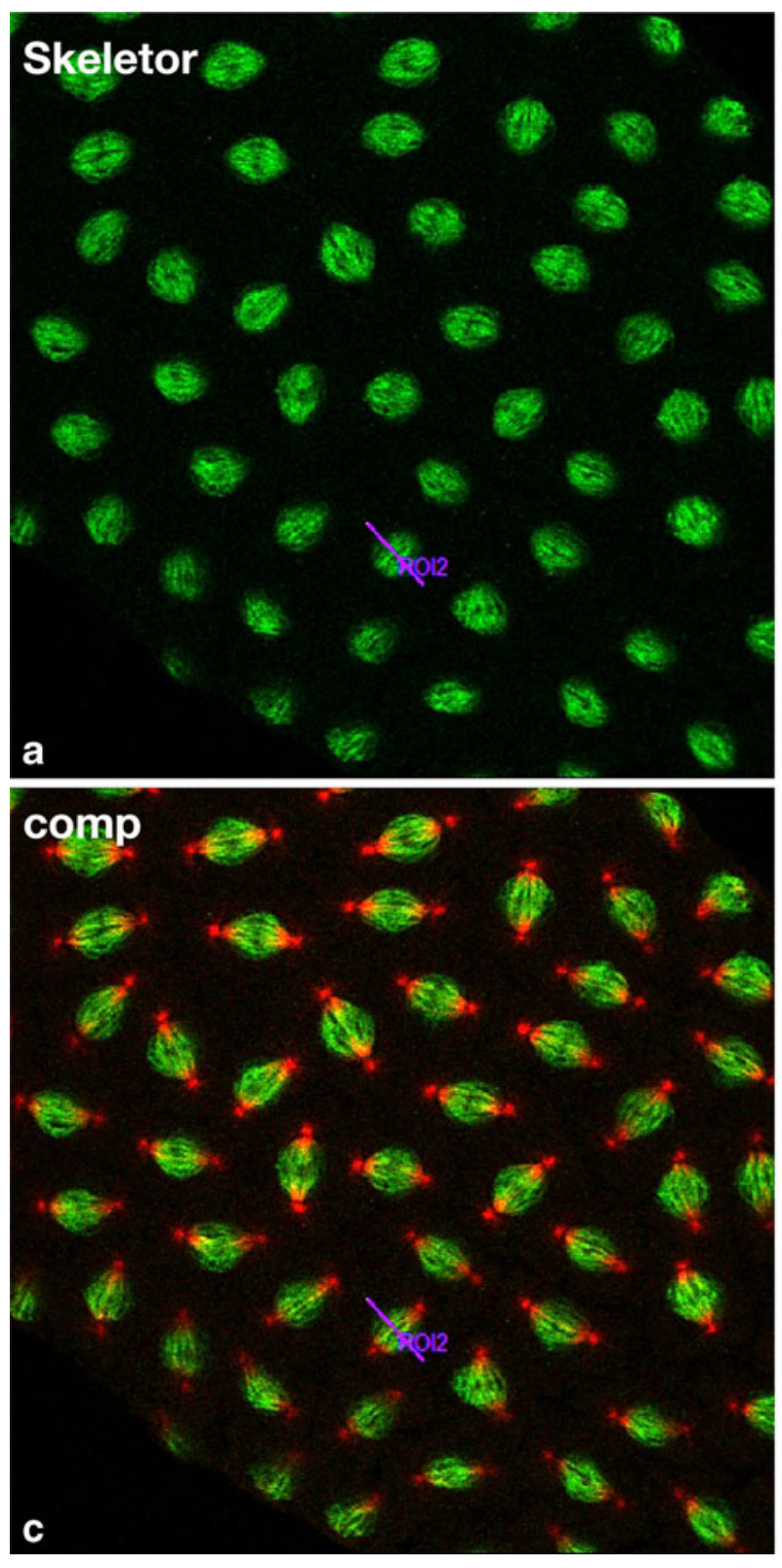

Fig. 3 The spindle matrix and the microtubule spindle apparatus do not co-localize but rather appear co-aligned. a-c Metaphase embryo double labeled with antibody (mAb 1A1) to the spindle matrix protein Skeletor (in green) and with an antibody to tubulin (in red). d Linescan of the pixel-intensity

length of in vitro spindles, although an anisotropic matrix cannot be ruled out. Furthermore, they conclude it is unlikely that a weak isotropic matrix is present throughout the spindle (although it may exist at the poles), given that the spindle moved at the rate of microtubule flux until decreasing in velocity at the
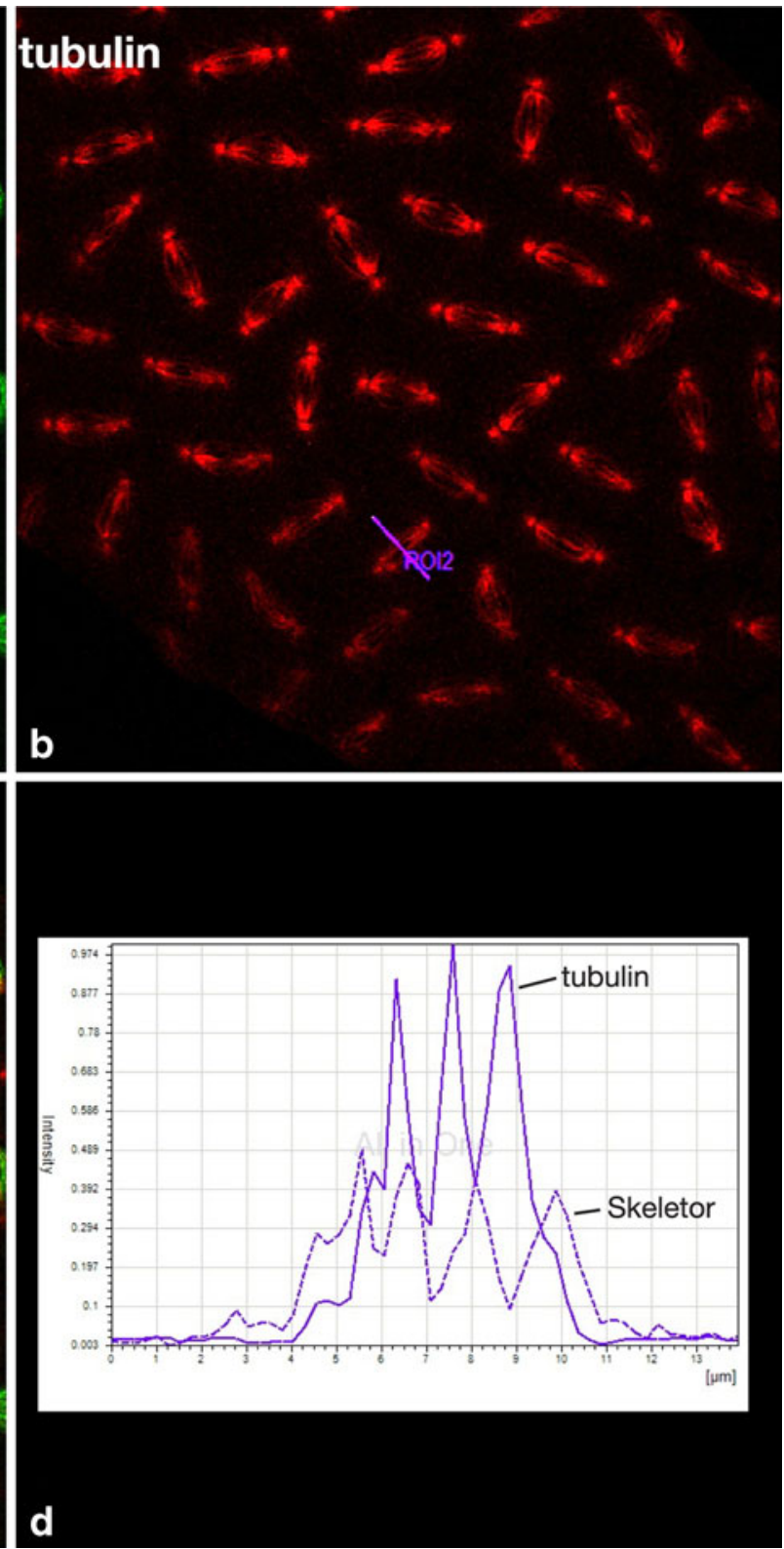

across the spindle of the Skeletor and tubulin labeling of one of the metaphase spindles (ROI2) indicating their co-alignment. The confocal images shown are from preparations obtained as described in Walker et al. (2000)

poles. While the observed results do appear to rule out a "strong," unyielding anisotropic matrix they would not be inconsistent with the existence of a pliable matrix comprised of an elastic hydrogel. Interestingly, the transient collapse of the nucleoporin barrier by an optimal nuclear transport receptor-cargo complex can 
allow cargo to pass through the nuclear pore at the rate of diffusion (Ribbeck and Görlich 2001). Thus, under certain conditions, reorganization of a hydrogel can occur on a very rapid time scale.

\section{Control of spindle length}

Despite that microtubules are constantly undergoing dramatic fluctuations in length due to dynamic instability, the spindle maintains a uniform size that is consistent within a given cell type, though spindle length may vary in different cells within the same organism or at different developmental stages (reviewed in Webster et al. 2009). What determines spindle size and how it is maintained is not known but microtubule dynamics may play a role. Spindle shortening was observed after blocking plus-end polymerization with taxol or depleting the CLASP kinetochore protein (Waters et al. 1996; Maiato et al. 2005). Spindle lengthening was observed after interfering with kinesin- 8 or kinesin-13 family members' microtubuledepolymerizing activities (Walczak et al. 1996; Straight et al. 1998; Savoian et al. 2004; Goshima et al. 2005) or katanin's microtubule-severing activity (McNally et al. 2006). Inhibiting either inward or outward sliding of overlapping antiparallel microtubules resulted in spindle lengthening or shortening, respectively, upon perturbation of kinesin-5 or kinesin-14 family members (Sharp et al. 2000; Mountain et al. 1999). Thus, regulation of microtubule architecture clearly impacts spindle length; however, numerous studies have shown that microtubule length does not directly set the spindle length since microtubules have been found to bend or buckle within the spindle under various conditions. In klp67A mutants in Drosophila, elongated microtubules become bent and wavy as if something is constraining microtubule extension (Savoian et al. 2004). In spindles treated with hexylene glycol or antibodies against MCAK, both of which result in microtubules (and spindles) growing in length, a large number of microtubules curve or buckle as the spindle elongates (Mitchison et al. 2005). Indeed, the bending or curving of a microtubule in response to some internal constraint on spindle length may promote length-dependent microtubule depolymerization, consistent with the observed increased efficiency of binding of kinesin-13 to curved microtubule protofilaments (Mulder et al. 2009).

An alternative approach has been to examine mechanical and elastic properties of spindles upon application or withdrawal of compressive forces perpendicular to their pole-to-pole axis. Using quantitative perturbations with a piezo-resistive cantilever system, Itabashi et al. (2009) found that Xenopus meiotic spindles behave at metaphase like a viscoelastic or plastic structure. Moreover, Dumont and Mitchison (2009) observed that somatic mitotic spindle shape changes occurring after application of a controlled, compressive force on top of the spindle are characterized by two distinct stages: within the first $\sim 3-4 \mathrm{~min}$ spindles widened even in the presence of taxol, whereas over a time-frame of $\sim 12 \mathrm{~min}$, spindles lengthened in a tubulin polymerization-dependent process that occurred at a rate consistent with poleward flux. Several features of this study are particularly noteworthy: during the initial passive spindle-widening stage, the microtubules splay outwards, suggesting some other component (such as a spindle matrix?) is holding the poles at a fixed distance. After spindles have reached full extension to their new length, continued time-lapse imaging revealed a significant degree of wavy microtubules and microtubule buckling, suggesting the spindle is constrained from achieving yet a larger size. But what is responsible for this internal limit on microtubule extension? Perhaps this new length is defined once an elastic spindle matrix has been stretched to its full extension by the lengthening microtubules. Once the force applied on top of the spindle is released, the spindle returns to its original size suggesting that whatever originally determined "proper spindle size" remained intact. One possibility to explain this behavior could be that a stretched-out spindle matrix would return to its original state once external forces are removed. Computational modeling of arrays of FG-Nups revealed that initially fully extended segments would coil up and shorten into an intercrossing, brush-like structure that continued to undergo random conformational transitions once extension forces are released (Miao and Schulten 2009). Although the aim of modeling FG-Nup behavior for this particular study was to characterize the "resting state" of FG-Nups within the nuclear pore channel, the observed lengthening and shortening behavior of FG-Nups upon application and relaxation, respectively, of an artificial extension force could also be viewed in terms of a model in which FG-Nups might contribute to elastic forces that influence spindle length. For example, growing 
microtubules might "stretch" the spindle matrix until eventually the force level required for further stretching (unfolding) induces microtubule buckling, thus stimulating kinesin-13-related microtubule depolymerization activities that serve to limit microtubule spindle length. In this scenario there would need to be some kind of "connection" between the spindle matrix and microtubules. Yao et al. (2010) have recently provided evidence that at least one spindle matrix protein in Drosophila indeed has a microtubule-binding domain and can be co-purified with microtubules.

Another possibility for generating elastic forces within the spindle matrix would be the presence of titin. Titin is a humongous molecule consisting primarily of Ig-repeat, FN3-repeat, and PEVK domains that has been found in both the nucleus and associated with the spindle (Mechado and Andrew 2000; Fabian et al. 2007a; Qi et al. 2004; Zhong et al. 2010). In muscles, titin is thought to act as a "molecular spring", lengthening due to unfolding of these domains when stretching forces are applied, but shortening after these domains spontaneously refold when stretching forces are lowered (reviewed in Linke and Grützner 2008).

It should be emphasized, however, that many different factors contribute to control of mitotic spindle length, and for a thorough discussion of relevant molecules and mechanisms, the reader is referred to Goshima and Scholey (2010). Although the correlation breaks down for very large cells such as in Xenopus or Drosophila embryos, in general the prevailing view is that cell size determines spindle size with an upper limit of $\sim 60 \mu \mathrm{m}$ (Wühr et al. 2008). However, if rather than viewing the mitotic spindle solely as a "cytoplasmic structure," one instead considers it to be a structure based equally on a remodeled nuclear architecture joined by a remodeled microtubule cytoskeleton (Johansen and Johansen 2009), perhaps a correlation of spindle size with nuclear size will prove more universal. Brown et al. (2007) noted that differences in spindle matrix architecture could underlie the variations that are observed within different cells of a single organism or between closely related species and more recently Levy and Heald (2010) have found that the same kind of size scaling that is observed between spindles of $X$. laevis and $X$. tropicalis is found between their nuclei as well. In fact, it has long been appreciated that the size of a cell and its nucleus are related
(Gulliver 1875) and in yeast, for example, it was determined that the ratio of average nuclear volume to average cell volume as a cell grows in size is quite consistent (Jorgensen et al. 2007; Neumann and Nurse 2007). This relationship holds up over expansive evolutionary distances independent of DNA content (Cavalier-Smith 2005) but the mechanism underlying this phenomenon was not known. Recently, however, nuclear scaling was found to arise due to differences in nuclear transport mechanisms (Levy and Heald 2010). Given that the concentration of nuclear architectural proteins available to construct a spindle matrix would in general increase concomitantly with nuclear size, it seems plausible that the amount of nuclear proteins available to form the spindle matrix may be the major determinant of spindle size.

A poly-ADP-ribose containing gel matrix?

Other components besides proteins also have been proposed to be part of the spindle matrix. Work from the Mitchison lab (Chang et al. 2004) revealed a requirement for poly(ADP-ribose) (PAR), a heterogeneous linear or irregularly branched polymer of up to 200 ADP-ribose moieties (D'Amours et al. 1999), in the assembly and maintenance of spindle bipolarity. Either RNAi depletion of the PAR polymerase (PARP) tankyrase-1 or reduction of PAR levels by overexpression of the PAR glycohydrolase (PARG) results in a range of defects including splayed or multipolar spindles, increased spindle length, pole curling, and even complete loss of spindle bipolarity (Chang et al. 2004, 2005b). The underlying mechanism by which decrease in PARylation levels leads to defects in spindle morphology is not known. However, the spindle matrix protein NuMA has been identified as a major acceptor of the poly(ADP-ribosyl)ation modification and, in addition, can directly bind to PAR moieties (Chang et al. 2005a; Chang and Coughlin 2009). These findings suggest that poly(ADP-ribosyl) ation could potentially function in dynamic crosslinking of neighboring NuMA molecules to assist with spindle pole focusing (Chang and Coughlin 2009). Furthermore, the presence of such sugar polymers could be envisioned to modulate the visco-elastic properties of a gel matrix.

Interestingly, loss of PARylation did not impair NuMA or Eg5 localization to the spindles, nor did it 
interfere with Mad2 recruitment to kinetochores or activation of the spindle checkpoint (Chang et al. 2004). These results suggest that the Megator/Tpr spindle matrix that is required for proper Mad2 checkpoint signaling (Lee et al. 2008; Lince-Faria et al. 2009; De Souza et al. 2009) is likely to still be intact. However, the curling and twisting exhibited by microtubules at the poles indicate the existence abnormal torsional forces when PARylation is impaired (Chang et al. 2005b). One possible explanation may be that PARylation is required for certain molecules to navigate unimpeded through the gel-like spindle matrix and in the absence of this modification transport through the spindle is disrupted, thus impairing proper focusing of the spindle poles and proper balancing of the forces and counterforces necessary to maintain proper spindle length and bipolarity.

UV microbeam studies and the possibility of actin/ myosin as spindle matrix components

The hypothesis that the spindle matrix is an elastic gel implies that its contractile properties would tend to bring spindle poles closer together. Indeed, in the findings of UV microbeam experiments that spindle poles move together after all the microtubules in newt half-spindles are severed (Spurck et al. 1990) and that spindles collapse toward the equator in C. elegans oocytes when kinetochores are removed from all bivalents (Dumont et al. 2010) are consistent with this idea. However, UV microbeam experiments discussed above have also suggested that matrix forces ostensibly act in the other direction, acting to propel kinetochore fibers and stubs to the spindle pole (Spurck et al. 1997). This raises the possibility that motile systems other than the microtubule-based apparatus such as the actinmyosin motility system may be involved in spindle function, either as a direct part of the spindle matrix or in collaboration with the matrix.

For example, irradiation of kinetochore fibers with an ultraviolet microbeam creates kinetochore fiber stubs, remnants of the kinetochore fibers that remain attached to the kinetochore but are severed from the pole. When kinetochore stubs are created in anaphase, anaphase chromosomes that are connected to the stub continue to move at normal speeds (e.g., Forer 1966; Spurck et al. 1997) or, in some cells, accelerate (Gordon and Inoué 1979; Gordon 1980; Izutsu 1988; Spurck et al. 1997; Chen and Zhang 2004). In the context of the spindle matrix hypothesis, the interpretation is that forces from the matrix propel the kinetochore fiber poleward, that the rate of chromosome motion is limited by depolymerisation of the intervening kinetochore microtubules, and that when the microtubules are severed and do not extend to the pole, the speed due to matrix forces is not limited by intervening microtubules so the chromosomes accelerate. When stubs are created in metaphase the associated chromosome sometimes moves toward the pole on the irradiated side, which can similarly be attributed to matrix forces: without intervening microtubules to prevent movement the chromosome is propelled poleward. Sometimes chromosomes associated with metaphase stubs remain at the equator (e.g., Maiato et al. 2004; Forer 1965, 1966); for these chromosomes, the interkinetochore distances remain the same, so this indicates that the poleward force from the stub is the same as that from the non-severed kinetochore fiber going to the opposite pole, which again can be attributed to forces from the matrix acting on the stub. Tubulin subunits add to kinetochore stubs at the kinetochore (Maiato et al. 2004), so metaphase stubs elongate. Microtubule elongation is stimulated by external forces (Franck et al. 2007) which might arise from the matrix, and interestingly pharmacological inhibitors of the actin-myosin system block elongation of the kinetochore stub (Forer et al. 2007), thus implicating actin-myosin in spindle and matrix function.

Abundant evidence has accumulated that actin and myosin (including activated (phosphorylated) myosin) are present in spindles in general and kinetochore fibers in particular (reviews in Forer et al. 2003; Woolner and Bement 2009; Dulyaninova et al. 2004; Weber et al. 2004; Fabian et al. 2007b; Fabian and Forer 2007; Woolner et al. 2008; Vilmos et al. 2009), as are proteins that interact in actin-myosin function such as titin (Fabian et al. 2007a), Band 4.1 (Krauss et al. 1997), zyxin (Hirota et al. 2000), myosin light chain kinase (Dulyaninova et al. 2004), and moesin (Vilmos et al. 2009). Actin and myosin interact with microtubules in a variety of other motile situations (e.g., Rodriguez et al. 2003; Weber et al. 2004; Pizon et al. 2005; Woolner and Bement 2009) so it would not be surprising were they to interact with spindle microtubules. Not only are they present in spindles but a variety of experimental perturbations has also implicated them in spindle function (reviewed in Forer et al. 2003; Pickett-Heaps 
and Forer 2009; Woolner and Bement 2009; Ma et al. 2010). For example, interfering with actin and/or myosin alters anaphase chromosome movement, blocks anaphase onset, and alters spindle shapes, chromosome attachment, and chromosome distributions. It is difficult to explain such a variety of results that implicate actin and myosin as due solely to effects on microtubules; rather, the results point to important roles of actin and myosin in spindle functioning. Might actin and myosin be part of a spindle matrix?

Actin, myosin, and titin are present in nuclei and seem to function in maintaining nuclear structure and in moving chromosomes inside nuclei (e.g., Mehta et al. 2010; Zhong et al. 2010). Thus, they are similar to the other spindle matrix proteins being discussed here in being in nuclei prior to mitosis and in the spindle during mitosis, and it is not inconceivable that they interact with other spindle matrix proteins and microtubules in setting up the spindle. Actin itself can form gels (e.g., Janmey et al. 1994) that could support or be a part of the spindle matrix. In starfish oocytes, actin, and myosin form a network ("matrix") that, when anchored at one position, moves chromosomes from the position of the former nucleus to the mitotic spindle at the surface of the cell, up to 20-30 $\mu \mathrm{m}$ away, at speeds near those of anaphase chromosomes (Lénárt et al. 2005; Mori et al. 2010). The network does not move the chromosomes in any direction when it is not anchored (Mori et al. 2010), so if a similar network existed in the spindle, it might be the microtubules and spindle poles which provide the directionality. Spindles remove granules and other not-attached components by transporting them to the poles at speeds near those of anaphase chromosomes (Bajer 1967; Nicklas and Koch 1972; LaFountain et al. 2001), a property shared with the actomyosin network in star fish oocytes, which moves "inert" granules to the anchor point in the same manner (and same speed) that it moves chromosomes (Mori et al. 2010). Thus, it is conceivable that actin and myosin contribute to or actively participate in the spindle matrix.

Do the distributions of actin and myosin match those of the matrix proteins? There is little data that compare them directly. Filamentous actin has been studied and is present near matrix proteins in some species (Fabian et al. 2007a; Fabian and Forer 2007) but little is known about total actin in spindles. Myosin is present in spindles (for example, Silverman-Gavrila and Forer 2003; Fabian and Forer 2005, 2007; Woolner et al. 2008; Sandquist and Bement 2010) and phosphorylated (active) myosin is concentrated in the spindle, near kinetochore fibers (Fabian et al. 2007a, b). Thus, the limited data are consistent with actin and myosin interacting with or being part of the spindle matrix.

Membranes and the spindle matrix

The potential contribution of membranes to spindle form and function has not been extensively addressed but a number of independent studies have found evidence for membranous structures present in some but not all spindles (Hepler 1989). In some studies, vesicular or tubular membrane elements were found to permeate the spindle and/or ensheathe the chromosomes (Moll and Paweletz 1980; Rieder and Nowogrodzki 1983; Wise and Wolniak 1984; Paweletz and Fehst 1984; Waterman-Storer et al. 1993) while in other cases membranes formed a "spindle envelope" encasing the spindle (Hepler 1980; Wise and Wolniak 1984; Motzko and Ruthmann 1984; Stafstrom and Staehelin 1984; Harel et al. 1989; Kremer and Hawley 2003). From these studies, it is not clear whether the membrane association with the spindle plays a functional role or is simply a way to apportion membrane components to daughter nuclei. However, the report of a functional requirement for a transmembrane protein associated with a spindle envelope (Kremer and Hawley 2003) suggests the potential for an operative role in at least some spindle types.

In a recent screen in fission yeast to identify mutants unable to form stable diploid cells, a novel gene, ned $1+$ was isolated which when mutated gives rise to highly deformed nuclei, overdeveloped endoplasmic reticulum (ER)-like membranes, a high incidence of chromosome missegregation, and increased sensitivity to microtubule destabilization (Tange et al. 2002). Remarkably, this gene was found to encode the yeast homolog of lipin, a highly conserved phosphatidic acid phosphohydrolase, dysfunctions of which are associated with lipodystrophy in humans and mice. In this study, Tange et al. (2002) determined that Ned1 interacts with components of the Ran-GTP system known to be important in a number of processes including bipolar spindle assembly, nuclear envelope formation, and nuclear transport (reviewed in Clarke and Zhang 2008) as well as interacting with Nup189, the $S$. pombe homolog of the mammalian GLFG-Nup98. Overexpression of ned1+ resulted in nuclear elongation due to formation of a long microtu- 
bule bundle within the interphase nucleus (Tange et al. 2002). The nuclear elongation was a consequence of this unusual microtubule structure since upon microtubule disassembly, nuclear shape returned to a rounded form. Mild depletion of lipin by RNAi in C. elegans also results in abnormalities in nuclear shape and disorganization of the endoplasmic reticulum, with the appearance of membranous sheets replacing the normal mitotic tubular structures (Golden et al. 2009). Strikingly, there were also spindle abnormalities and failure in pronuclear fusion events. Severely depleted animals showed more extreme phenotypes of abnormal chromosome segregation, irregular chromosome movements, and aberrant nuclear envelope reassembly, often encasing individual chromosomes or subsets of chromosomes (Golden et al. 2009).

Why does a mutation that affects lipid biosynthesis result in spindle defects? In systems displaying an open mitosis lacking a nuclear membrane, the nuclear envelope is absorbed into the ER which itself undergoes a sheet-to-tubule transformation exhibiting a very different structure characterized by more branch points and shorter profiles (Puhka et al. 2007). In 3-D reconstructions of mitotic cells Puhka et al. (2007) observed the reticulated ER to be denser and more evenly distributed throughout the cell apart from areas occupied by the chromosomes and mitotic spindle. However, in other studies, vesicular or tubular membranes were described as permeating the spindle and/or ensheathing the chromosomes (Moll and Paweletz 1980; Rieder and Nowogrodzki 1983; Wise and Wolniak 1984). Lipid bilayers will tend to adopt a flat conformation because generation of curvature requires energy. Thus, tubulation or vesiculation typically is mediated by proteins that generate membrane curvature either by hydrophobic insertion mechanisms or by scaffolding mechanisms (reviewed in Shibata et al. 2009). Presumably excess ER membrane biosynthesis that occurs in lipin mutants exceeds the capacity of the membrane-bending proteins to remodel the ER during mitosis into tubules and, in closed mitotic systems such in yeast, introduces defects in the nuclear envelope that may interfere with SPB function. Interestingly, the scaffold ring of the nuclear pore complex contains four nucleoporins that share a domain that is related to an ancestral coatamer element such as found in vesicle coats like COPII (DeGrasse et al. 2009) and recently, depletion of epsin, an endocytic adaptor protein that induces membrane curvature, was shown to result in a range of spindle aberrations (Liu and Zheng 2009).

Reorganization of nuclear envelope and ER membranes may contribute to mitotic spindle function in several different ways. Firstly, a very dense, reticulated network surrounding the spindle may provide a barrier function, restricting access to and from the spindle. Secondly, the potential energy stored within curved membranes may contribute to viscoelastic forces acting upon the spindle. And thirdly, a membranous matrix may provide a critical structure to sequester essential mitotic factors as well as partition membrane systems during cell division (Zheng and Tsai 2006; Zheng 2010). Indeed, lamin B comprises a vesiculate membraneous network that surrounds the microtubule spindle during mitosis in a number of different systems including Xenopus (Tsai et al. 2006) and has been shown to sequester spindle assembly factors that are released in a Ran-GTP-regulated process (Tsai et al. 2006). Furthermore, modeling of in vitro and in vivo data suggests that an elastic and dynamic lamin-B envelope could act antagonistically on plus-enddirected motors to assist in both focusing and stabilizing the microtubule spindle at least during early stages of mitosis in Drosophila (Civelekoglu-Scholey et al. 2010; Poirier et al. 2010). Depletion of lamin B resulted in a range of spindle assembly defects including elongated or multi-polar spindles as well as half spindles or asters, whereas antibody cross-linking of lamin Dm0 (the Drosophila lamin B homolog) into a hyperstable network impeded spindle elongation (Tsai et al. 2006; Goodman et al. 2010; Civelekoglu-Scholey et al. 2010). Although the membranous spindle matrix appears to be distinct from the internal spindle matrix (reviewed in Zheng 2010), both structures arise from the remodeling of nuclear architectural proteins and may have the potential to exhibit viscoelastic properties that can confer compressive or resistive forces onto the spindle.

\section{Evolutionary conservation and function of spindle matrix proteins}

One concern that has been raised against the concept of a spindle matrix is that many of the components identified in one system do not appear to have obvious homologs in other systems, raising the question of how "important" a candidate spindle 
matrix protein is if it appears to be unique to a given model system. Regarding this concern, it should be noted that until structural data were available to show immunoglobulin domains exhibit the same overall folding structure as cadherin domains (Overduin et al. 1995), the level of sequence divergence between these two domains suggested there would be no similarity between the two motifs whatsoever! So the failure to identify obvious homologs by sequence comparisons does not necessarily imply lack of existence of functional homologs. This point is further underscored when considering that although yeast and vertebrate NPCs share many obviously homologous components, searches by sequence similarity in distant taxa have identified surprisingly few NPC components. However, recent proteomic analysis of fractionated NPCs in a divergent eukaryote, Trypanosoma brucei, found conservation of protein-fold type, overall domain organization, composition, and modularity (DeGrasse et al. 2009). Especially noteworthy, the natively unfolded, unstructured FG-Nups showed extraordinarily high rates of amino acid substitutions that confounded in silico homology identification (DeGrasse et al. 2009), which is consistent with what had already been noted as an overall trend exhibited by FG-Nup family members (Denning and Rexach 2007).

Thus, it may not be a fruitful endeavor to seek potential spindle matrix proteins by sequence comparison, especially for components of the spindle matrix that are characterized by unstructured, natively unfolded domains. Nevertheless, a notable exception to this is the Tpr protein, which localizes to the mitotic spindle in a wide range of different systems spanning from yeast to filamentous fungi to plants to animals (Niepel et al. 2005; Jiménez et al. 2000; Xu et al. 2007; De Souza et al. 2009; Qi et al. 2004; Lee et al. 2008; Lince-Faria et al. 2009). Furthermore, studies in many of these systems report a critical role for the respective Tpr homolog in spindle function.

In Drosophila depletion of Megator by RNAi in S2 cells leads to reduction in the mitotic index and impaired checkpoint signaling, with both Mad2 and Mps1 failing to properly associate with unattached kinetochores (Qi et al. 2004; Lince-Faria et al. 2009). Since Mad2 co-immunoprecipitates with Megator, this could suggest that one of the roles of the spindle matrix is to properly target checkpoint signaling proteins during open and semi-open mitosis (Lince-Faria et al. 2009; De Souza and Osmani 2009). This is also true in human cells where Tpr was identified by mass spec as a Mad2-associated factor (Lee et al. 2008). Human Tpr directly binds both Mad1 and Mad2, and its depletion disrupts Mad1 localization to the kinetochores. Like Megator, human Tpr localizes to mitotic spindles (Sauer et al. 2005; Lince-Faria et al. 2009). Intriguingly, human Tpr has recently been reported to directly interact with dynein (Nakano et al. 2010).

Tpr homologs have also been identified in both budding and fission yeast. In Saccharomyces cerevisiae, there are two such homologs called Mlp1 and Mlp2 (myosin-like protein). Mlp2p binds to the yeast spindle pole body (SPB) and promotes its efficient maturation; depletion of Mlp2p results in shortened and defective spindles, abnormal numbers of microtubule organizers, and stochastic failures in cell division (Niepel et al. 2005). In $S$. pombe there are also two homologs, Nup211 and alm1, with alm1 corresponding to Mlp2 and localizing to the SPB and mitotic midzone (Jiménez et al. 2000; Ding et al. 2000). Disruption of alm1p leads to mitotic defects and an inability to germinate (Jiménez et al. 2000), although whether this is associated with defects in SPB maturation as in the case of budding yeast has not yet been examined. Nevertheless, the recent report that although fission yeast can undergo nuclear division in the absence of spindle microtubules, this "back-up" mechanism for chromosome segregation requires a mature SPB (Castagnetti et al. 2010) raises provocative questions as to whether a spindle matrix may be involved.

The Tpr homolog in the Aspergillus nidulans fungal system, known as An-Mlp1, has been much more extensively studied with respect to its mitotic role. An-Mlp1 localizes to both a spindle matrix and the kinetochores and, like Drosophila and mammalian Tpr homologs, is required for spatial regulation of spindle assembly checkpoint proteins (De Souza et al. 2009; De Souza and Osmani 2009). Significantly, when cells that have been treated to depolymerize microtubules enter mitosis, An-Mlp1 still accumulates normally in an expanded region around the kinetochore cluster where the prophase spindle would have formed, indicating that the An-Mlp1 spindle matrix is a distinct entity from the microtubule spindle (De Souza et al. 2009). Furthermore, An-Mlp1 retains a pool of AnMad1 around the spindle through telophase, suggesting the spindle matrix plays a role in spatiotemporal regulation of the SAC throughout mitosis, for example to regulate mitotic exit and to coordinate postmitotic 
nucleolus disassembly (De Souza et al. 2009; De Souza and Osmani 2009).

\section{Concluding remarks}

From the numerous studies reviewed here, there appears little doubt that nuclear proteins reorganize during mitosis to form a structure independent from that of the microtubule-based spindle apparatus that contributes to proper chromosome segregation. Here, we propose that this structure may take the form of an elastic, hydrogel-like matrix. This hypothesis in theory would be able to account for most if not all of the recently described dynamic and malleable features of the spindle matrix. However, for this hypothesis to be viable, many questions remain to be answered in future experiments. Especially, it needs to be determined whether the known spindle matrix proteins physically can form such a loosely crosslinked gel matrix with the viscoelastic properties necessary to counteract forces produced by the microtubule spindle apparatus while at the same time allowing for chromosome movement.

Acknowledgements We thank members of the laboratory for discussion, advice, and critical reading of the manuscript. The authors' work on the spindle matrix is supported by NSF grant MCB0817107.

\section{References}

Ader C, Frey S, Maas W, Schmidt HB, Görlich D, Baldus M (2010) Amyloid-like interactions with nucleoporin FG hydrogels. Proc Natl Acad Sci USA 107:6281-6285

Bajer A (1967) Notes on ultrastructure and some properties of transport within the living mitotic spindle. J Cell Biol 33:713-720

Baktrakou DG, Kerr ARW, Schirmer EC (2009) Comparative proteomic analysis of the nuclear envelope and pore complex suggests a wide range of heretofore unexpected functions. J Proteomics 72:56-70

Blower MD, Nachury M, Heald R, Weis K (2005) A Rae1containing ribonucleoprotein complex is required for mitotic spindle assembly. Cell 121:223-234

Brown KS, Blower MD, Maresca TJ, Grammer TC, Harland RM, Heald R (2007) Xenopus tropicalis egg extracts provide insight into the scaling of the mitotic spindle. $\mathrm{J}$ Cell Biol 176:765-770

Castagnetti S, Oliferenko S, Nurse P (2010) Fission yeast cells undergo nuclear division in the absence of spindle microtubules. PLoS Biol 8:e1000512
Cavalier-Smith T (2005) Economy, speed, and size matter: evolutionary forces driving nuclear genome miniaturization and expansion. Ann Bot (Lond) 95:147-175

Chang P, Coughlin MTJ (2009) Interaction between Poly(ADPribose) and NuMA contributes to mitotic spindle pole assembly. Mol Biol Cell 20:4575-4585

Chang P, Jacobson MK, Mitchison TJ (2004) Poly(ADP-ribose) is required for spindle assembly and structure. Nature 432:645-649

Chang W, Dynek JN, Smith S (2005a) NuMA is a major acceptor of poly(ADP-ribosyl)ation by tankyrase 1 in mitosis. Biochem J 391:177-184

Chang P, Jacobson MK, Mitchison TJ (2005b) Tankyrase-1 polymerization of poly(ADP-ribose) is required for spindle structure and function. Nat Cell Biol 7:1133-1139

Chen W, Zhang D (2004) Kinetochore fiber dynamics outside the context of the spindle during anaphase. Nat Cell Biol 6:227-231

Civelekoglu-Scholey G, Tao L, Brust-Mascher I, Wollman R, Scholey JM (2010) Prometaphase spindle maintenance by an antagonistic motor-dependent force balance made robust by a disassembling lamin-B envelope. J Cell Biol 188:49-68

Clarke PR, Zhang C (2008) Spatial and temporal coordination of mitosis by Ran-GTPase. Nature Rev Mol Cell Biol 9:464-477

D'Amours D, Desnoyers S, D’Silva I, Poirier GG (1999) Poly (ADP-ribosyl)ation reactions in the regulation of nuclear functions. Biochem J 342:249-268

De Souza CP, Osmani SA (2009) Double duty for nuclear proteins - the price of more open forms of mitosis. Trends Genet 25:545-554

De Souza CP, Hashmi SB, Nayak T, Oakley B, Osmani SA (2009) Mlp1 acts as a mitotic scaffold to spatially regulate spindle assembly checkpoint proteins in Aspergillus nidulans. Mol Biol Cell 20:2146-2159

DeGrasse JA, DuBois KN, Devos D, Siegel TN, Sali A, Field MC, Rout MP, Chait BT (2009) Evidence for a shared nuclear pore complex architecture that is conserved from the last common eukaryotic ancestor. Mol Cell Proteomics 8:2119-2130

Denning DP, Rexach MF (2007) Rapid evolution exposes the boundaries of domain structure and function in natively unfolded FG nucleoporins. Mol Cell Proteomics 6:272-282

Denning DP, Patel SS, Uversky V, Fink AL, Rexach M (2003) Disorder in the nuclear pore complex: the FG repeat regions of nucleoporins are natively unfolded. Proc Natl Acad Sci USA 100:2450-2455

Desai A, Murray A, Mitchison TJ, Walczak CE (1999) The use of Xenopus egg extracts to study mitotic spindle assembly and function in vitro. Methods Cell Biol 61:385-412

Ding DQ, Tomita Y, Yamamoto A, Chikashige Y, Haraguchi T, Hiraoka Y (2000) Large-scale screening of intracellular protein localization in living fission yeast cells by the use of a GFP-fusion genomic DNA library. Genes Cells 5:169-190

Ding Y, Yao C, Lince-Faria M, Rath U, Cai W, Maiato H, Girton J, Johansen KM, Johansen J (2009) Chromator is required for proper microtubule spindle formation and mitosis in Drosophila. Dev Biol 334:253-263

Dulyaninova NG, Patskovsky YV, Bresnick AR (2004) The $\mathrm{N}$-terminus of the long MLCK induces a disruption in 
normal spindle morphology and metaphase arrest. J Cell Sci 117:1481-1493

Dumont S, Mitchison TJ (2009) Compression regulates mitotic spindle length by a mechanochemical switch at the poles. Curr Biol 19:1086-1095

Dumont J, Oegema K, Desai A (2010) A kinetochoreindependent mechanism drives anaphase chromosome separation during acentrosomal meiosis. Nat Cell Biol 12:894-901

Fabian L, Forer A (2005) Redundant mechanisms for anaphase chromosome movements: crane-fly spermatocyte spindles normally use actin filaments but also can function without them. Protoplasma 225:169-184

Fabian L, Forer A (2007) Possible roles of actin and myosin during anaphase chromosome movements in locust spermatocytes. Protoplasma 231:201-213

Fabian L, Troscianczuk J, Forer A (2007a) Calyculin A, an enhancer of myosin, speeds up chromosome movement. Cell Chromosome 6:1

Fabian L, Xia X, Venkitaramani DV, Johansen KM, Johansen J, Andrew DJ, Forer A (2007b) Titin in insect spermatocyte spindle fibers associates with microtubules, actin, myosin, and the matrix proteins skeletor, megator, and chromator. J Cell Sci 120:2190-2204

Fontoura BM, Dales S, Blobel G, Zhong H (2001) The nucleoporin Nup98 associates with the intranuclear filamentous protein network of TPR. Proc Natl Acad Sci USA 98:3208-3213

Forer A (1965) Local reduction of spindle fiber birefringence in living Nephrotoma suturalis (Loew) spermatocytes induced by ultraviolet microbeam irradiation. J Cell Biol 25:95-117

Forer A (1966) Characterization of the mitotic traction system, and evidence that birefringent spindle fibers neither produce nor transmit force for chromosome movement. Chromosoma 19:44-98

Forer A (1974) Possible roles of microtubules and actin-like filaments during cell division. In: Padilla GM, Cameron IL, Zimmerman A (eds) Cell cycle controls. Academic, New York, pp 319-336

Forer A, Goldman RD (1969) Comparisons of isolated and in vivo mitotic apparatuses. Nature 222:689-691

Forer A, Spurck T, Pickett-Heaps JD, Wilson PJ (2003) Structure of kinetochore fibres in crane-fly spermatocytes after irradiation with an ultraviolet microbeam: neither microtubules nor actin filaments remain in the irradiated region. Cell Motil Cytoskeleton 56:173-192

Forer A, Spurck T, Pickett-Heaps J (2007) Actin and myosin inhibitors block elongation of kinetochore fibre stubs inmetaphase crane-fly spermatocytes. Protoplasma 232:79-85

Franck AD, Powers AF, Gestaut DR, Gonen T, Davis TN, Asbury CL (2007) Tension applied through the Dam1 complex promotes microtubule elongation providing a direct mechanism for length control in mitosis. Nat Cell Biol 9:832-837

Frey S, Görlich D (2007) A saturated FG-repeat hydrogel can reproduce the permeability properties of nuclear pore complexes. Cell 130:512-523

Frey S, Görlich D (2009) FG/FxFG as well as GLFG repeats form a selective permeability barrier with self-healing properties. EMBO J 28:2554-2567
Frey S, Richter RP, Görlich D (2006) FG-repeats of nuclear pore proteins form a three-dimensional meshwork with hydrogel-like properties. Science 314:815-817

Fridkin A, Penkner A, Jantsch V, Gruenbaum Y (2009) SUNdomain and KASH-domain proteins during development, meiosis and disease. Cell Mol Life Sci 66:1518-1533

Gatlin JC, Matov A, Danuser G, Mitchison TJ, Salmon ED (2010) Directly probing the mechanical properties of the spindle and its matrix. J Cell Biol 188:481-489

Golden A, Liu J, Cohen-Fix O (2009) Inactivation of the C. elegans lipin homolog leads to ER disorganization and to defects in the breakdown and reassembly of the nuclear envelope. J Cell Sci 122:1970-1978

Goldman RD, Rebhun LI (1969) The structure and some properties of the isolated mitotic apparatus. J Cell Sci 4:179-210

Goodman B, Channels W, Qiu M, Iglesias P, Yang G, Zheng Y (2010) Lamin B counteracts the kinesin Eg5 to restrain spindle pole separation during spindle assembly. J Biol Chem 285:35238-35244

Gordon GW (1980) The control of chromosome motion: UV microbeam irradiation of kinetochore fibers. Thesis, University of Pennsylvania

Gordon GW, Inoué S (1979) Unexpected increase in poleward velocities of mitotic chromosomes after UV irradiation of their kinetochore fibers. J Cell Biol 83:376

Goshima G, Scholey JM (2010) Control of mitotic spindle length. Annu Rev Cell Dev Biol 26:21-57

Goshima G, Wollman R, Stuurman N, Scholey JM, Vale RD (2005) Length control of the metaphase spindle. Current Biol 15:1979-1988

Gulliver G (1875) Observations on the sizes and shapes of the red corpuscles of the blood of vertebrates, with drawings of them to a uniform scale, and extended and revised tables of measurements. Proc Zool Soc Lond 1875:474495

Han Z, Liang CG, Cheng Y, Duan X, Zhong Z, Potireddy S, Moncada C, Merall S, Latham KE (2010) Oocyte spindle proteomics analysis leading to rescue of chromosome congression defects in cloned embryos. J Proteome Res 9:6025-6032

Harel A, Zlotkin E, Nainudel-Epszteyn S, Feinstein N, Fisher P, Gruenbaum Y (1989) Persistence of major nuclear envelope antigens in an envelope-like structure during mitosis in Drosophila melanogaster embryos. J Cell Sci 94:463-470

Hashizume C, Nakano H, Yoshida K, Wong RW (2010) Characterization of the role of the tumor marker Nup88 in mitosis. Mol Cancer 9:119

Heald R, Tournebize R, Blank T, Sandaltzopoulos R, Becker P, Hyman A, Karsenti E (1996) Self-organization of microtubules into bipolar spindles around artificial chromosomes in Xenopus egg extracts. Nature 382:420-425

Hepler P (1980) Membranes in the mitotic apparatus of barley cells. J Cell Biol 86:490-499

Hepler P (1989) Membranes in the mitotic apparatus. In: Hymans JS, Brinkley BR (eds) Mitosis: moelcules and mechansims. Academic, Sand Diego, pp 241-271

Hirota T, Morisaki T, Nishiyama T, Marumoto T, Tada K, Hara T, Masuko N, Inagaki M, Hatakayema K, Saya $\mathrm{H}$ (2000) Zyxin, a regulator of actin filament 
assembly, targets the mitotic apparatus by interacting with h-warts/LATS1 tumor suppressor. J Cell Biol 149:1073-1086

Inoué S, Ritter H (1975) Dynamics of mitotic spindle organization and function. In: Inoué S, Stephens RE (eds) Molecules and cell movement. Raven, New York, pp 3-29

Itabashi T, Takagi J, Shimamoto Y, Onoe H, Kuwana K, Shimoyama I, Gaetz J, Kapoor TM, Ishiwata S (2009) Probing the mechanical architecture of the vertebrate meiotic spindle. Nat Methods 6:167-172

Izutsu K (1988) Changes of chromosomal spindle (kinetochore) fibers and the behaviour of bivalent chromosomes in grasshopper spermatocytes after irradiation of the kineotchores with an ultraviolet microbeam. Protoplasma $1: 122-132$

Janmey PA, Hvidt S, Käs J, Lerche D, Maggs A, Sackmann E, Schliwa M, Stossel TP (1994) The mechanical properties of actin gels. Elastic modulus and filament motions. J Biol Chem 269:32503-32513

Jeganathan KB, Malureanu L, van Deursen JM (2005) The Rae1-Nup98 complex prevents aneuploidy by inhibiting securin degradation. Nature 438:1036-1039

Jiménez M, Petit T, Gancedo C, Goday C (2000) The alm1+ gene from Schizosaccharomyces pombe encodes a coiled-coil protein that associates with the medial region during mitosis. Mol Gen Genet 262:921-930

Johansen KM, Johansen J (2002) Recent glimpses of the elusive spindle matrix. Cell Cycle 1:312-314

Johansen KM, Johansen J (2007) Cell and molecular biology of the spindle matrix. Int Rev Cytol 263:155-206

Johansen J, Johansen KM (2009) The spindle matrix through the cell cycle in Drosophila. Fly 3:1-8

Jorgensen P, Edgington NP, Schneider BL, Rupes I, Tyers M, Futcher B (2007) The size of the nucleus increases as yeast cells grow. Mol Biol Cell 18:3523-3532

Joseph J, Dasso M (2008) The nucleoporin Nup358 associates with and regulates interphase microtubules. FEBS Lett 582:190-196

Joseph J, Tan SH, Karpova TS, McNally JG, Dasso M (2002) SUMO-1 targets RanGAP1 to kinetochores and mitotic spindles. J Cell Biol 156:595-602

Kane RE, Forer A (1965) The mitotic apparatus. Structural changes after isolation. J Cell Biol 25(Suppl):31-39

Katsani KR, Karess RE, Dostatni N, Doye V (2008) In vivo dynamics of Drosophila nuclear envelope components. Mol Biol Cell 19:3652-3666

Krauss SW, Larabell CA, Lockett S, Gascard P, Penman S, Mohandas N, Chasis JA (1997) Structural protein 4.1 in the nucleus of human cells: dynamic rearrangements during cell division. J Cell Biol 137:275-289

Kremer J, Hawley RS (2003) The spindle-associated transmembrane protein Axs identifies a membranous structure ensheathing the meiotic spindle. Nat Cell Biol 5:261263

Krishnan VV, Lau EY, Yamada J, Denning DP, Patel SS, Colvin ME, Rexach MF (2008) Intramolecular cohesion of coils mediated by phenylalanine-glycine motifs in the natively unfolded domain of a nucleoporin. PLoS Comp Biol 4: e1000145

LaFountain JR Jr, Oldenbourg R, Cole RW, Rieder CL (2001) Microtubule flux mediates poleward motion of acentric chromosome fragments during meiosis in insect spermatocytes. Mol Biol Cell 12:4054-4065

Lee SH, Sterling H, Burlingame A, McCormick F (2008) Tpr directly binds to Mad1 and Mad2 and is important for the Mad1-Mad2-mediated mitotic spindle checkpoint. Genes Dev 22:2926-2931

Lénárt P, Bacher CP, Daigle N, Hand AR, Eils R, Terasaki M, Ellenberg J (2005) A contractile nuclear actin network drives chromosome congression in oocytes. Nature 436:812-818

Leslie RJ, Hird RB, Wilson L, McIntosh JR, Scholey JM (1987) Kinesin is associated with a nonmicrotubule component of sea urchin mitotic spindles. Proc Natl Acad Sci USA 84:2771-2775

Levy DL, Heald R (2010) Nuclear size is regulated by importin $\alpha$ and Ntf2 in Xenopus. Cell 143:288-298

Lince-Faria M, Maffini S, Orr B, Ding Y, Florindo C, Sunkel CE, Tavares A, Johansen J, Johansen KM, Maiato $\mathrm{H}$ (2009) Spatiotemporal control of mitosis by the conserved spindle matrix protein Megator. J Cell Biol 184:647-657

Linke WA, Grützner A (2008) Pulling single molecules of titin by AFM - recent advances and physiological implications. Pflügers Arch Eur J Physiol 456:101-115

Liu Z, Zheng Y (2009) A requirement for epsin in mitotic membrane and spindle organization. J Cell Biol 186:473480

Lohka MJ, Maller JL (1985) Induction of nuclear envelope breakdown, chromosome condensation, and spindle formation in cell-free extracts. J Cell Biol 101:518-523

Ma X, Jana SS, Conti MA, Kawamoto S, Claycomb WC, Adelstein RS (2010) Ablation of nonmuscle myosin II-B and II-C reveals a role for nonmuscle myosin II in cardiac myocyte karyokinesis. Molec Biol Cell 21:39523962

Maiato H, Rieder C, Khodjakov A (2004) Kinetochore-driven formation of kinetochore fibers contributes to spindle assembly during animal mitosis. J Cell Biol 167:831-840

Maiato H, Khodjakov A, Rieder CL (2005) Drosophila CLASP is required for the incorporation of microtubule subunits into fluxing kinetochore fibres. Nat Cell Biol 7:42-47

McNally K, Audhya A, Oegema K, McNally FJ (2006) Katanin controls mitotic and meiotic spindle length. J Cell Biol 175:881-891

Mechado C, Andrew DJ (2000) D-titin: a giant protein with dual roles in chromosomes and muscles. J Cell Biol 151:639-652

Mehta IS, Amira M, Harvey AJ, Bridger JM (2010) Rapid chromosome territory relocation by nuclear motor activity in response to serum removal in primary human fibroblasts. Genome Biol 11:R5

Merdes A, Ramyar K, Vechio JD, Cleveland DW (1996) A complex of NuMA and cytoplasmic dynein is essential for mitotic spindle assembly. Cell 87:447-458

Merdes A, Heald R, Samejima K, Earnshaw WC, Cleveland DW (2000) Formation of spindle poles by dyneindynactindependent transport of NuMA. J Cell Biol 149:851-862

Miao L, Schulten K (2009) Transport-related strctures and processes of the nuclear pore complex studied through molecular dynamics. Structure 17:449-459

Miao L, Schulten K (2010) Probing a structural model of the nuclear pore comoplex channel through molecular dynamics. Biophys J 98:1658-1667 
Mishra RK, Chakraborty P, Arnaoutov A, Fontoura BM, Dasso M (2010) The Nup107-160 complex and gamma-TuRC regulate microtubule polymerization at kinetochores. Nat Cell Biol 12:164-169

Mitchell PJ, Cooper CS (1992) The human tpr gene encodes a protein of 2094 amino acids that has extensive coiled-coil regions and an acidic C-terminal domain. Oncogene 7:2329-2333

Mitchison TJ (2005) Mechanism and function of poleward flux in Xenopus extract meiotic spindles. Philos Trans R Soc Lond B Biol Sci 360:623-629

Mitchison TJ, Maddox P, Gaetz J, Groen A, Shirasu M, Desai A, Salmon ED, Kapoor TM (2005) Roles of polymerization dynamics, opposed motors, and a tensile element in governing the length of Xenopus extract meiotic spindles. Mol Biol Cell 16:3064-3076

Moll E, Paweletz N (1980) Membranes of the mitotic apparatus of mammalian cells. Eur J Cell Biol 21:280-287

Mori M, Monnier N, Daigle N, Bathe M, Ellenberg J, Lenart P (2010) A network of contractile F-actin units drives intracellular transport in starfish oocytes. Mol Biol Cell 21:1128

Morone N, Fugiwara T, Murase K, Kasai RS, Ike H, Yuasa S, Usukura J, Kusumi A (2006) Three-dimensional reconstruction of the membrane skeleton at the plasma membrane interface by electron tomography. J Cell Biol 174:851-862

Motzko D, Ruthmann A (1984) Spindle membranes in mitosis and meiosis of the heteropteran insect Dysdercus intermedius. A study of the interrelationship of spindle architecture and the kinetic organization of chromosomes. Eur J Cell Biol 33:205-216

Mountain V, Simerly C, Howard L, Ando A, Schatten G, Compton DA (1999) The kinesin-related protein, HSET, opposes the activity of Eg5 and cross-links microtubules in the mammalian mitotic spindle. J Cell Biol 147:351-366

Mulder AM, Glavis-Bloom A, Moores CA, Wagenbach M, Carragher B, Wordeman L, Milligan RA (2009) A new model for binding of kinesin 13 to curved microtubule protofilaments. J Cell Biol 185:51-57

Nakano H, Funasaka T, Hashizume C, Wong RW (2010) Nucleoporin translocated promoter region (Tpr) associates with dynein complex, preventing chromosome lagging formation during mitosis. J Biol Chem 285: 10841-10849

Neumann FR, Nurse P (2007) Nuclear size control in fission yeast. J Cell Biol 179:593-600

Nicklas RB (1975) Chromosome movements: current models and experiments on living cells. In: Inoué S, Stephens RE (eds) Molecules and cell movement. Raven, New York, pp 97-107

Nicklas RB (1983) Measurements of the force produced by the mitotic spindle in anaphase. J Cell Biol 97:542-548

Nicklas RB, Koch CA (1972) Chromosome micromanipulation. IV. Polarized motions within the spindle and models for mitosis. Chromosoma 39:1-26

Niepel M, Strambio-de-Castillia C, Fasolo J, Chait BT, Rout MP (2005) The nuclear pore complex-associated protein, Mlp2p, binds to the yeast spindle pole body and promotes its efficient assembly. J Cell Biol 170:225235
Orjalo AV, Arnaoutov A, Shen Z, Boyarchuk Y, Zeitlin SG, Fontoura B, Briggs S, Dasso M, Forbes DJ (2006) The Nup107-160 nucleoporin complex is required for correct bipolar spindle assembly. Mol Biol Cell 17:3806-3818

Overduin M, Harvey TS, Bagby S, Tong KI, Yau P, Takeichi M, Ikura M (1995) Solution structure of the epithelial cadherin domain responsible for selective cell adhesion. Science 267:386-389

Paddy MR, Saumweber H, Agard DA, Sedat JW (1996) Timeresolved, in vivo studies of mitotic spindle formation and nuclear lamina breakdown in Drosophila early embryos. J Cell Sci 109:591-607

Paweletz N, Fehst M (1984) The vesicular compartment of the mitotic apparatus in mammalian cells. Cell Biol Int Rep 8:675-688

Pickett-Heaps J, Forer A (2009) Mitosis: spindle evolution and the matrix model. Protoplasma 235:91-99

Pickett-Heaps JD, Tippit DH (1980a) Light and electron microscopic observations on cell division in two large pennate diatoms. Hantzschia and Nitzschia. II. Ultrastructure. European J Cell Biol 21:12-27

Pickett-Heaps JD, Tippit DH (1980b) Light and electron microscopic observations on cell division in two large pennate diatoms. Hantzschia and Nitzschia. I. Mitosis in vivo. European J Cell Biol 21:1-11

Pickett-Heaps JD, Tippit DH, Porter KR (1982) Rethinking mitosis. Cell 29:729-744

Pickett-Heaps JD, Spurck T, Tippit DH (1984) Chromosome motion and the spindle matrix. J Cell Biol 99:137s$143 \mathrm{~s}$

Pickett-Heaps JD, Forer A, Spurck T (1996) Rethinking anaphase: where "PacMan" fails and why a role for the spindle matrix is likely. Protoplasma 192:1-10

Pickett-Heaps JD, Forer A, Spurck T (1997) Traction fibre: toward a "tensegral" modle of the spindle. Cell Motil Cytoskel 37:1-6

Pizon V, Gerbal F, Diaz CC, Karsenti E (2005) Microtubuledependent transport and organization of sarcomeric myosin during skeletal muscle differentiation. EMBO J 24:37813792

Poirier CC, Zheng Y, Iglesias PA (2010) Mitotic membrane helps to focus and stabilize the mitotic spindle. Biophys J 99:3182-3190

Puhka M, Vihinen H, Joensuu M, Jokitalo E (2007) Endoplasmic reticulum remains continuous and undergoes sheet-to-tubule transformation during cell division in mammalian cells. $\mathrm{J}$ Cell Biol 179:895-909

Qi H, Rath U, Wang D, Xu Y-Z, Ding Y, Zhang W, Blacketer M, Paddy M, Girton J, Johansen J, Johansen KM (2004) Megator, an essential coiled-coil protein localizes to the putative spindle matrix during mitosis. Mol Biol Cell 15:4854-4865

Qi H, Rath U, Ding Y, Ji Y, Blacketer MJ, Girton J, Johansen J, Johansen KM (2005) EAST interacts with Megator and localizes to the putative spindle matrix during mitosis in Drosophila. J Cell Biochem 95:1284-1291

Rath U, Wang D, Ding Y, Xu Y-Z, Blacketer MJ, Girton J, Johansen J, Johansen KM (2004) Chromator, a novel and essential chromodomain protein interacts directly with the spindle matrix protein skeletor in Drosophila. J Cell Biochem 93:1033-1047 
Rebhun LI, Palazzo RE (1988) In vitro reactivation of anaphase $\mathrm{B}$ in isolated spindles of sea urchin egg. Cell Motil Cytoskel 10:197-209

Ribbeck K, Görlich D (2001) Kinetic analysis of translocation through nuclear pore complexes. EMBO J 20:1320-1330

Rieder CL, Nowogrodzki R (1983) Intranuclear membranes and the formation of the first meiotic spindle in Xenos peckii (Acroschismus wheeleri) oocytes. J Cell Biol 97:1144-1155

Rodriguez OC, Schaefer AW, MandatoCA FP, Bement WM, Waterman-Storer CM (2003) Conserved microtubule-actin interactions in cell movement and morphogenesis. Nature Cell Biol 5:599-609

Rost B, Yachdav G, Liu J (2004) The PredictProtein server. Nucleic Acids Res 32:W321-W326

Rout MP, Aitchison JD, Suprapto A, Hjertaas K, Zhao Y, Chait BT (2000) The yeast nuclear pore complex: composition, architecture, and transport mechanism. J Cell Biol 148:635-651

Salina D, Enarson P, Rattner JB, Burke B (2003) Nup358 integrates nuclear envelope breakdown with kinetochore assembly. J Cell Biol 162:991-1001

Sandquist JC, Bement W (2010) Characterizing the role of myosin-10 in regulating mitotic spindle structure and function. Mol Biol Cell 21:832

Sauer G, Körner R, Hanisch A, Ries A, Nigg EA, Silljé HW (2005) Proteome analysis of the human mitotic spindle. Mol Cell Proteomics 4:35-43

Savoian MS, Gatt MK, Riparbelli MG, Callaini G, Glover DM (2004) Drosophila KLP67A is required for proper chromosome congression and segregation during meiosis I. J Cell Sci 117:3669-3677

Sawin KE, Mitchison TJ (1991) Mitotic spindle assembly by two different pathways in vitro. J Cell Biol 112:925-940

Sharp DJ, Brown HM, Kwon M, Rogers GC, Holland G, Scholey JM (2000) Functional coordination of three mitotic motors in Drosophila embryos. Mol Biol Cell 11:241-253

Shibata Y, Hu J, Kozlo MM, Rapoport TA (2009) Mechanisms shaping the membranes of cellular organelles. Annu Rev Cell Dev Biol 25:329-354

Sillers PJ, Forer A (1983) Action spectrum for changes in spindle fibre birefrigence after ultraviolet microbeam irradiations of single chromosomal spindle fibres in crane-fly spermatocytes. J Cell Sci 62:1-25

Silverman-Gavrila RV, Forer A (2003) Myosin localization during meiosis I of crane-fly spermatocytes gives indications about its role in division. Cell Motil Cytoskeleton 55:97-113

Snyder JA, Armstrong L, Stonington OG, Spurck TP, Pickett-Heaps JD (1991) UV-microbeam irradiations of the mitotic spindle: spindle forces and structural analysis of lesions. Europ J Cell Biol 55:122-132

Spurck T, Stonington OG, Snyder JA, Pickett-Heaps JD, Bajer A, Molé-Bajer J (1990) UV microbeam irradiations of the mitotic spindle. II. Spindle fiber dynamics and force production. J Cell Biol 111:1505-1518

Spurck T, Forer A, Pickett-Heaps J (1997) Ultraviolet microbeam irradiations of epithelial and spermatocyte spindles suggest that forces act on the kinetochore fibre and are not generated by its disassembly. Cell Motil Cytoskel 36:136-148
Stafstrom JP, Staehelin LA (1984) Dynamics of the nuclear envelope and of nuclear pore complexes during mitosis in the Drosophila embryo. Eur J Cell Biol 34:179-189

Steffen W, Linck RW (1992) Evidence for a non-tubulin spindle matrix and for spindle components immunologically related to tektin filaments. J Cell Sci 101:809-822

Straight AF, Sedat JW, Murray AW (1998) Time-sapse microscopy reveals unique roles for kinesins during anaphase in budding yeast. J Cell Biol 143:687-694

Strawn LA, Shen T, Shulga N, Goldfarb DS, Wente SR (2004) Minimal nuclear pore complexes define FG repeat domains essential for transport. Nat Cell Biol 6:197-206

Tange Y, Hirata A, Niwa O (2002) An evolutionarily conserved fission yeast protein, Ned1, implicated in normal nuclear morphology and chromosome stability, interacts with Dis3, Pim1/RCC1 and an essential nucleoporin. J Cell Sci 115:4375-4385

Terry LJ, Wente SR (2009) Flexible gates: dynamic topologies and functions for FG nucleoporins in nucleocytoplasmic transport. Euk Cell 8:1814-1827

Tippit DH, Picket-Heaps JD, Leslie R (1980) Cell division in two large pennate diatoms Hantzschia and Nitzschia III. A new proposal for kinetochore function during prometaphase. J Cell Biol 86:402-416

Tsai MY, Wang S, Heidinger JM, Shumaker DK, Adam SA, Goldman RD, Zheng Y (2006) A mitotic lamin B matrix induced by RanGTP required for spindle assembly. Science 311:1887-1893

Vilmos P, Jankovics F, Szathmári M, Lukácsovich T, Henn L, Erdélyi M (2009) Live imaging reveals that the Drosophila actin-binding ERM protein, moeisin, co-localizes with the mitotic spindle. Europ J Cell Biol 88:609-619

Walczak CE, Mitchison TJ, Desai A (1996) WKCM1: A Xenopus kinesin-related protein that regulates microtubule dynamics during mitotic spindle assembly. Cell 84:37-47

Walker DL, Wang D, Jin Y, Rath U, Wang Y, Johansen J, Johansen KM (2000) Skeletor, a novel chromosomal protein that redistributes during mitosis provides evidence for the formation of a spindle matrix. J Cell Biol 151:1401-1411

Wasser M, Chia W (2003) The Drosophila EAST protein associates with a nuclear remnant during mitosis and constrains chromosome mobility. J Cell Sci 116:17331743

Waterman-Storer CM, Sanger JW, Sanger JM (1993) Dynamics of organelles in the mitotic spindles of living cells: membrane and microtubule interactions. Cell Motil Cytoskeleton 26:19-39

Waters JC, Mitchison TJ, Rieder CL, Salmon ED (1996) The kinetochore microtubule minus-end disassembly associated with poleward flux produces a force that can do work. Mol Biol Cell 7:1547-1558

Weber KL, Sokac AM, Berg JS, Cheney RE, Bement WM (2004) A microtubule-binding myosin required for nuclear anchoring and spindle assembly. Nature 431: 325-329

Webster M, Witkin KL, Cohen-Fix O (2009) Sizing up the nucleus: nuclear shape, size and nuclear-envelope assembly. J Cell Sci 122:1477-1486

Wein H, Bass HW, Cande WZ (1998) DSK1, a kinesin-related protein involved in anaphase spindle elongation is a 
component of a mitotic spindle matrix. Cell Motil Cytoskeleton 41:214-224

Wise D, Wolniak SM (1984) A calcium-rich intraspindle membrane system in spermatocytes of wolf spiders. Chromosoma 90:50-56

Woolner S, Bement WM (2009) Unconventional myosins acting unconventionally. Trends Cell Biol 19:245-252

Woolner S, O’Brien LL, Wiese C, Bement WM (2008) Myosin-10 and actin filaments are essential for mitotic spindle function. $\mathrm{J}$ Cell Biol 182:77-88

Wühr M, Chen C, Dumont S, Groen AC, Needleman DJ, Salic A, Mitchison TJ (2008) Evidence for an upper limit to mitotic spindle length. Curr Biol 18:1256-1261

Xu S, Powers MA (2010) Nup98-homeodomain fusions interact with endogenous Nup98 during interphase and localize to kinetochores and chromosome arms during mitosis. Mol Biol Cell 21:1585-1596

$\mathrm{Xu} \mathrm{XM}$, Rose A, Muthuswamy S, Jeong SY, Vekatakrishnan S, Zhoa Q, Meier I (2007) Nuclear pore anchor, the
Arabidopsis homolog of Tpr/Mlp1/Mlp2/Megator, is involved in mRNA export and SUMO homeostasis and affects diverse aspects of plant development. Plant Cell 19:1537-1548

Yao C, Ding Y, Rath U, Sharp D, Girton J, Johansen J, Johansen KM (2010) Chromator, a chromosomally derived spindle matrix complex protein contains both histone $\mathrm{H} 1$ and tubulin binding domains. Mol Biol Cell 21:1961

Zheng Y (2010) A membranous spindle matrix orchestrates cell division. Nat Rev Mol Cell Biol 11:529-535

Zheng Y, Tsai M-Y (2006) The mitotic spindle matrix: a fibromembranous lamin connection. Cell Cycle 5:2345-2347

Zhong Z, Wilson KL, Dahl KN (2010) Beyond lamins other structural components of the nucleoskeleton. Methods Cell Biol 98:97-119

Zimowska G, Aris JP, Paddy MR (1997) A Drosophila Tpr homolog is localized both in the extrachromosomal channel network and to the nuclear pore complexes. J Cell Sci 110:927-944 